\title{
Editorial
}

\section{Substance use and cancer}

\author{
Ravindra Fernando
}

Editor-in-Chief email: ravindrafernando@hotmail.co.uk

An aspect of substance use disorders that does not receive much attention is the potential of some such substances to cause cancer.

It is well known that alcohol use can cause cancers of the mouth, pharynx, oesophagus, liver, breast, colon and rectum. Alcohol may also increase the risk of cancer of the pancreas. There is evidence of a positive association between alcohol drinking and upper aerodigestive tract cancer mortality, especially when alcohol consumption reaching moderate-to-heavy level. ${ }^{1}$

Exposure to environmental tobacco smoke during adult life increases risk of lung cancer in lifetime nonsmokers. It has been shown that tobacco use by spouse was associated with a $30 \%$ excess risk of lung cancer. ${ }^{2}$

Extensive studies over the years have proved that betel nut and its components, primarily the alkaloid arecoline, as a carcinogen. These substances not only have general mutagenic, cytotoxic and genotoxic properties, but are also intricately involved in enzymatic, molecular and genetic mechanisms that result in the development of cancers at various sites, specifically in the oral cavity. ${ }^{3}$

Studies suggest that cannabis smoking may be a risk factor for lung cancer, but tobacco smoking or other potential confounders may explain part of the increased risk. $^{4}$

It is reported that "heavy" cannabis smoking was significantly associated with more than a twofold risk (hazard ratio 2.12, 95 \% CI 1.08-4.14) of developing lung cancer over a 40-year follow-up period, even after statistical adjustment for baseline tobacco use, alcohol use, respiratory conditions, and socioeconomic status. ${ }^{5}$

Amphetamines may play a role in the development of lymphoma by further suppressing the immune systems of HIV positive people. It is also possible that amphetamines have the ability to directly trigger the development of lymphoma.

Researchers, who analysed the "American Multicenter AIDS Cohort", which has been monitoring the health of men at risk for and who have HIV infection since the early 1980s, found that men who used amphetamine frequently (once 
weekly or more) were nearly five times more likely to develop lymphoma than men who did not use amphetamine as often. This link was statistically significant. ${ }^{6}$ Further studies on the immunologic and cancer-causing potential of amphetamine on both HIV negative and HIV positive people are recommended.

The incidence of oral squamous cell carcinoma has been long associated with smoking, alcohol, and betel quid/areca nut chewing. A case of a 42-year-old female patient with squamous cell carcinoma of the floor of the mouth, associated with khat (derived from the plant Catha edulis) chewing has been reported. With the changing demographic structure and migration between countries, khat chewing is of increasing significance in developed countries. ${ }^{7}$

Therefore, in addition to other harmful socio-economic effects of substance use, carcinogenicity is also an important health factor that has to be considered. Public health measures in cancer prevention and control should address these factors in planning their future programmes.

\section{Reference}

1. Alcohol drinking and upper aerodigestive tract cancer mortality: A systematic review and meta-analysis. Li Y, Mao Y, Zhang Y et al Oral Oncol. 2014 Jan 6. pii: S1368-8375(13)00803-8.

Doi: 10.1016/j. [Epub ahead of print]

2. Environmental tobacco smoke and lung cancer in nonsmoking women. A multicenter study. Fontham ET, Correa P, Reynolds P, Wu-Williams A, Buffler PA, Greenberg RS, Chen VW, Alterman T, Boyd P, Austin DF, et al. JAMA. 1994;271(22):1752-9.

3. Association of betel nut with carcinogenesis: revisit with a clinical perspective. Sharan RN, Mehrotra R, Choudhury Y, Asotra K. PLoS One. 2012;7(8):e42759.

Doi: 10.1371/journal.pone.0042759. Epub 2012 Aug 13.

4. Cannabis smoking and risk of lung cancer in men: a pooled analysis of three studies in Maghreb. Berthiller J, Straif K, Boniol M et al. J Thorac Oncol. 2008;3(12):1398-403.

Doi: 10.1097/JTO.0b013e31818ddcde. 
5. Marijuana use and risk of lung cancer: a 40-year cohort study. Callaghan RC, Allebeck P, Sidorchuk A. Cancer Causes Control. 2013;24(10):1811-20.

Doi: 10.1007/s10552-013-0259-0. Epub 2013 Jul 12.

6. Retrieved from http://www.thebodypro.com/content/art50146.html, on 22.01.2014

7. Oral squamous cell carcinoma associated with khat chewing. Fasanmade A, Kwok E, Newman L. Oral Surg Oral Med Oral Pathol Oral Radiol Endod. 2007;104(1):e53-5. Epub 2007 May 7. 